\title{
Pre-Service Teachers' Conceptual and Procedural Knowledge of Rational Numbers in E. P. College of Education, Bimbilla, Ghana
}

\author{
Anas Seidu Salifu \\ Department of Mathematics \& Information Communication Technology Education, Evangelical Presbyterian College of Education, Bimbilla, \\ Ghana
}

\section{Email address: \\ salifuanas@gmail.com}

\section{To cite this article:}

Anas Seidu Salifu. Pre-Service Teachers' Conceptual and Procedural Knowledge of Rational Numbers in E. P. College of Education, Bimbilla, Ghana. Education Journal. Vol. 10, No. 4, 2021, pp. 126-137. doi: 10.11648/j.edu.20211004.13

Received: May 26, 2021; Accepted: June 16, 2021; Published: July 16, 2021

\begin{abstract}
This study investigated Pre-Service Teachers' mastery level, achievements differences, and correlation of their procedural knowledge and conceptual knowledge of rational numbers. The population of the study was four hundred and twenty-nine (429) level 100 Pre-Service Teachers of Evangelical Presbyterian College of Education, Bimbilla. Descriptive research design was used, where both convenient and purposive sampling techniques were employed to select a sample of 75 . Out of the sample, 11 were females and 64 males representing $14.67 \%$ and $85.33 \%$ respectively. The instrument used was test items on conceptual and procedural knowledge on rational numbers designed by the researcher. The researcher used descriptive and inferential statistics to analyze the quantitative data, so as to answer the four research questions. The findings of the study indicated that the Pre-Service Teachers' conceptual knowledge and procedural knowledge mastery levels were at average-low and high-average levels respectively. Also, there was a significant difference between conceptual and procedural knowledge in rational numbers in favor of procedural knowledge with very high effect size. There was a weak positive correlation and no significant relationship between the Pre-Service Teachers' conceptual knowledge and procedural knowledge in rational numbers. The study recommended that College Tutors should be encouraged to adopt teaching methods and strategies that focus more on conceptual knowledge in rational numbers. Also, College Tutors evaluation exercises or assessment items should be balanced between conceptual knowledge and procedural knowledge because at the moment most assessment items are based on procedural knowledge to the neglect of conceptual knowledge assessment.
\end{abstract}

Keywords: Conceptual Knowledge, Procedural Knowledge, Pre-service Teachers (PSTs), Rational Numbers

\section{Introduction}

The Ministry of Education (MOE) in 2019 entreated teachers to ensure that students acquire mathematical knowledge and understanding through investigations, exploration, estimation, problem solving, project work and seminar presentation which will yield conceptual knowledge for students to be competent and skillful to solve problems and task in mathematics. The Ghanaian current curriculum 2018 has provided strategies for teaching and learning of Mathematics, that is fun and challenging for all grade levels. These strategies include (i) discussions of concepts and misconceptions, (ii) investigations to arrive at generalizations, (iii) problem-solving strategies, (iv) collaborative activities (think-pair-share), (v) multiple representations (Principle of multiple embodiment), (vi) establishing connections between and among related concepts, and (vii) using mathematical explorations, transitioning from number patterns to algebraic ideas.

Teachers in Colleges of Education in Ghana prior to 2018 were teaching and assessing Mathematics Content and Methodology separately but with the intervention of Transforming Teacher Education and Learning (T-TEL), Tutors are required to teach Mathematics Content and Methodology together. The T-TEL intervention designed the 2018 new curriculum and ensured its implementation, also placed more emphasis on both conceptual and procedural knowledge teaching and learning. It is in this light that, this study hinges on because rational number is taught in the first semester of level 100. For an effective classroom work, 
teaching and learning of rational numbers should promote good understanding of both conceptual and procedural knowledge because these body of knowledge are inseparable or are intertwined. In recent times, teaching at the Colleges of Education in Ghana has moved or shifted its attention towards a balance between procedural knowledge and conceptual knowledge understanding. This tallies with the 2018 new curriculum for all levels of the educational ladder in Ghana. Mathematics knowledge of concepts and procedures are signs of proficiency in the subject. The mastery of subject matter knowledge is essential for a preservice teacher to be effective and competent in teaching the subject. This is because the integration of the knowledge of both concepts and procedures consists of subject matter knowledge which is a prerequisite for teaching at the basic school level in Ghana. According to [22], they posited there is a bi-directional relation between conceptual and procedural knowledge because they complement one another. Similarly, [24] argued that some teachers find it difficult to distinguish between conceptual and procedural knowledge because of the similarities between them.

In most curriculum documents, a rational number is said to be any number that can be expressed in the form $\mathrm{a} / \mathrm{b}$ where $a$ and $b$ are integers and $\mathrm{b} \neq 0[19,20]$. The set of rational numbers forms part of the real number system and includes but is not limited to fractions and integers. Rational numbers have their application in relative measurement of length, mass, money, time and space [2, 29]. For instance, the calculation of relative distances between places, relative capacity of containers, interest rates on loans, savings and mortgages are daily usage of rational number sense. Aside its practical application, rational number sense enables further understanding of higher concepts in the elementary number system, algebra and analysis. Rational numbers are so important that, they serve as a spring board or foundation topic for algebra teaching and learning in Junior High Schools, Senior High Schools and Tertiary levels courses or subjects. In view of this, pre-tertiary mathematics curriculum requires learners to be exposed to rational numbers in a manner that extends their number sense and enable them to solve related problems [19].

An in-depth conceptual knowledge of the integer domain and fractions is a sign of proficiency in rational numbers [29]. However, research and assessment reports have highlighted various obstacles which relate to students, preservice teachers and practicing teachers' understanding of integers and fractions and by extension rational numbers. For example, students' difficulty in transitioning from whole numbers to the rational number field has been documented $[2,20]$. Also, over the years, college-level assessment reports indicated that most preservice teachers have little understanding of rational numbers [13]. This limited understanding tends to affect their overall performance in college-level mathematics and future teaching of rational numbers. [2] argues that limited understanding of rational numbers stems from conceptual and procedural imbalance which needs to be addressed by teachers.

This study is important because it will reveal the actual mastery levels of pre-service teachers in rational numbers because College Tutors are always confused when reports of pre-service teachers from the affiliate Universities indicates that PSTs have problems solving rational number problems. This study will also compare the PSTs performance in conceptual or procedural knowledge questions, which will inform teachers and stakeholders to find remedies to the identified problems. This study will assist tutors to know the relationship between conceptual and procedural knowledge which will guide them in setting questions.

\section{Literature Review}

Conceptual knowledge also referred to as knowledge of concepts, entails abstraction and generalization of particular instances. Similarly, [23] explain conceptual knowledge as the type of knowledge that offers an abstract comprehension of the principles and relations among bits of knowledge in an aspect. The definition of [23] corroborates the definition given by [15], where he defined conceptual knowledge as, "an abstract knowledge addressing the essence of mathematical principles and relations among them", (p. 182). Equally, [6] opined that conceptual knowledge-rich in relationships, can further be described as the basic mathematics constructs and relations between the ideas that exemplify mathematical procedures and meaning. Conceptual knowledge possessing goes beyond knowing or recalling certain definitions from memory, mathematical rules and procedures in mathematics. Preservice teachers only demonstrate conceptual knowledge understanding if they are able to defend why a mathematical statement is true or false can tell where a mathematical rule emanates from. Also, a person possesses conceptual knowledge if he/she is able to explain why and how of the procedures which are required for a logical and precise explanation of a mathematical problem. Based on the review of literature on conceptual knowledge in Mathematics, I will personally say that conceptual knowledge is being able to provide acceptable or admissible explanations to relationships among the concepts, definitions, and rules of mathematics.

"Knowing how or knowledge of the steps required to attain various goals" is knowledge of procedures, [22] p3. Also, [12] assert that knowing procedures, rules and algorithms essentially to solve mathematical problems reflects procedural knowledge. Similarly [10] opined that procedural knowledge in understanding mathematics is the knowledge that emphasizes skills and sequential steps without obvious reference to mathematical ideas. [15], cited [17] who explained procedural knowledge as "the ability to explain or justify the way one resolves a given problem without knowing the reason behind applying a certain theory, process or law during problem-solving process", (p. 182). From the discussion on Procedural knowledge reviews, I can conclude that, Procedural knowledge is when you grasp into memory the rules, procedures, principles, and definitions of mathematics, and be able to recall them when required to solve mathematical problems without necessarily comprehending them.

When [17] investigated teachers' knowledge of function 
concept, the outcome revealed that majority of the teachers had mastered procedural knowledge better than conceptual knowledge. His findings also concluded that the teachers' achievements on questions that required procedural knowledge were better than problems on conceptual knowledge.

In another study conducted by [11] in which she used 170 mathematics subject teachers from Kota Bharu, Malaysia, she reported that, $78.6 \%$ inexperienced teachers were at the low mastery level while were $60.7 \%$ experienced teachers achieved a high mastery level on conceptual knowledge. Her study further indicated that inexperienced teachers possessed procedural knowledge in mathematics and with a notion that a good mathematics teacher is one who can display systematic steps of a given calculation. Her finding also tallies those of [6] and [27]. Also, she stressed further that the inexperienced teachers are often regarded as those who use procedural knowledge a lot, whereas experienced teachers possess a combination of both procedural and conceptual knowledge. Finally, her study concluded that experienced teachers use a number of methods to assist their students to understand concepts by using many activities demanding students to participate in their own process of learning.

In a study conducted on procedural, conceptual and pedagogical knowledge on rational numbers, [6] used 15 preservice teachers in the United States of America as the participants. His study revealed that Pre-Service Teachers displayed a high operation levels of procedural knowledge and used common representations of rational numbers. Nonetheless, the Pre-Service Teachers demonstrated only a moderate to a high level of conceptual knowledge concerning rational numbers. Faulkenberry study asserted that the experienced Pre-Service Teachers encountered hitches in expressing a rational number as a ratio and as part of a region. The subjects also lacked the ability to explain the procedures used in solving problems. Furthermore, the study indicated that participants relied on procedures and algorithms and could not give reasons to justify why and how they applied to those methods. Similarly, [16] investigated students of the University of Anatolia, Turkey in a calculus course that focused on conceptual knowledge and procedural knowledge which indicated that students do not have sufficient comprehension of conceptual knowledge concerning integration topics in calculus. Also, the findings revealed that those students who did well on conceptual knowledge invariably performed well in procedural knowledge too.

Conceptual knowledge and procedural knowledge were investigated in Malaysia by [29] with a sample of 105 teachers from selected teacher-training colleges on the rational numbers. The findings showed that pre-service teachers' performance was above average level in conceptual and procedural knowledge. Their study revealed that the teachers had exhibited efficiency in fractions representation as part of a set, a region, and a ratio. Furthermore, they concluded that, the teachers also used their conceptual knowledge in solving life fraction problems and are able to draw one set when they are given a fraction representing a part. In a more similar recent study by [14] entitled "the conceptual and procedural knowledge of rational numbers in primary school teachers" concluded that the primary school mathematics teachers possessed a low level of conceptual knowledge and high level of procedural knowledge when 54 mathematics teachers were used as the sample in Bauchi Metropolis in Nigeria.

The findings in a study by [18] indicated statistically significant variation between conceptual knowledge and procedural knowledge which was in favor of latter when the study was conducted at the University of Yarmouk on undergraduate teachers. Their study concluded that the undergraduate teachers did not achieve the level of proficiency because their mean performance fell around $50 \%$ points from the test. In a similar study investigated by [1] revealed that teachers in secondary schools achieved an average degree of conceptual knowledge and are not able to use the simple facts and relationships when they are confronted with new situations. Also, a year later, [15] study entitled "Conceptual and Procedural Knowledge of Rational Numbers for Riyadh Elementary School Teachers", used 57 (27 novice Mathematics teachers and 30 experienced Mathematics teachers) as the sample which indicated that participants scored an average mark on conceptual and procedural knowledge with regards to rational numbers. Furthermore, his study analysis revealed that there was a statistically significant difference among the subjects in mean scores of conceptual knowledge and procedural knowledge. The students' performance in procedural knowledge test items was better than their conceptual knowledge test items. Also, the study concluded that there was no statistically significant relationship between the participants' conceptual knowledge and their procedural knowledge in rational numbers. Finally, there was a weak positive correlation between teachers' conceptual knowledge and their procedural knowledge concerning rational numbers achievements test.

In a research conducted by [5], examined the relationship between students' confidence in conceptual and procedural knowledge problems and used 235 students as the sample that completed an Introduction to Calculus course. The instrument used was test measuring the students' conceptual knowledge and procedural knowledge of graphs. The findings indicated that students did better in conceptual knowledge than in procedural knowledge. Their study also concluded that students had higher confidence in answering conceptual problems than their confidence in answering procedural problems. [28] whose study investigated Preservice elementary school teachers' knowledge of fraction: a mirror of students' knowledge that used a sample of 290 found that, the PSTs scores in procedural knowledge were significantly higher than their scores for conceptual knowledge. Their study concluded that PSTs lack the ability to explain the rationale of a procedure or the underlying conceptual meaning.

In another study by [3], entitled generating procedural and conceptual knowledge of fractions by preservice teachers 
with a sample of 109 and 114 for phase 1 and phase 2 respectively revealed that, PSTs who enter teacher education programs have prerequisite procedural knowledge of fractions and fraction operations but with limited conceptual knowledge of concepts and operations. Also, [4] examined that prospective teachers' content knowledge and pedagogical content knowledge on rational numbers, the relationship between content knowledge and pedagogical content knowledge, and differences in content knowledge and pedagogical content knowledge among prospective elementary teachers and lower secondary teachers found that there were gaps in prospective teachers' content knowledge and pedagogical content knowledge, a positive correlation between content knowledge and pedagogical content knowledge, and a better content knowledge but not pedagogical content knowledge for secondary compared to elementary school teachers.

\subsection{Statement of the Problem}

Pre-Service Teachers learn College Mathematics through their experiences and problems presented to them by their tutors in their classrooms. According to [25], several studies conducted on conceptual and procedural knowledge are mostly on counting, single-digit and multi-digit addition and subtraction of fractions. The following researchers $[8,9]$ and [21] also affirmed that most studies concentrated on conceptual and procedural knowledge of fractions. The significance of rational numbers in teaching and learning of mathematics is paramount in other aspect of mathematics hence investigating the E. P. College of Education PreService Teachers' conceptual and procedural knowledge of rational numbers will add knowledge to existing literature. Among the real number system sub- topics, teaching and learning of Rational number is the most problematic in the Colleges of Educations in Ghana. Also, it is evident that students find rational numbers problems difficult which also invariably make students dislike rational numbers hence lead to misconceptions of the topic.

For a pre-service teacher to succeed in the teaching profession and make his /her students develop positive attitudes towards mathematics then such a PST must possess both conceptual and procedural knowledge in mathematics which also includes rational numbers. Notwithstanding the Pre-Service Teachers' grasp of procedural knowledge, they equally need to attain an in-depth conceptual knowledge in Mathematics so as to be able to handle their future basic school pupils effectively. [26] and [16] have raised concerns about teachers not having a good comprehension of conceptual knowledge and procedural knowledge in mathematics. Mathematics Pre-Service Teachers' proficiency in both concepts and skills are not the only sufficient conditions for teacher's effectiveness, but an essential condition. Both conceptual knowledge and procedural knowledge are key to the training of mathematics preservice teachers in Ghana, without this Pre-Service Teachers cannot teach basic school mathematics effectively. Regrettably, some studies by [17] and [15] have revealed that students performed poorly in mathematical tasks demanding conceptual knowledge as compared to procedural knowledge. In Ghana, specifically, there is dearth of knowledge regarding PSTs rational number sense. Since rational numbers are the building blocks for learning nearly every aspect of mathematics, understanding PSTs rational number sense is imperative for pedagogical decisions. The gaps identified from the literature indicates that there are very few studies on rational numbers regarding conceptual and procedural knowledge in Africa as well as in Ghana, hence the motivation of the researcher to investigate Pre-Service Teachers' conceptual and procedural knowledge on rational numbers at E. P. College of Education, Bimbilla.

\subsection{Purpose of the Study}

The purpose of this study was to determine the mastery level of Pre-Service Teachers of E. P. College of EducationBimbilla, on conceptual and procedural knowledge of rational numbers. Also, the study sought to find out their achievement differences in conceptual and procedural knowledge of rational numbers. Finally, to determine the correlation between their scores on procedural and conceptual knowledge of rational numbers.

\subsection{Research Questions}

The study sought to answer the following four questions:

1. What is the level of Pre-Service Teachers' conceptual knowledge of rational numbers?

2. What is the level of Pre-Service Teachers' procedural knowledge of rational numbers?

3. Is there a significant difference between Pre-Service Teachers' conceptual knowledge and procedural knowledge in rational numbers?

4. Is there a significant correlation between Pre-Service Teachers' conceptual knowledge and their procedural knowledge regarding rational numbers?

\subsection{Hypotheses}

H01: There is no significant difference between the mean scores of pre-service teachers in conceptual and procedural knowledge of rational numbers.

H02: There is no significant relationship between the mean scores of pre-service teachers in conceptual and procedural knowledge of rational numbers.

\section{Methodology}

The study adopted a descriptive research design to explore Pre-Service Teachers' conceptual and procedural knowledge in rational numbers with purely quantitative data collection approach. The population was four hundred and twenty-nine (429) level 100 Pre-Service Teachers of the College. Both convenient and purposive sampling techniques were applied to select a sample of 75 Pre-Service Teachers. Out of the sample, 11 were females and 64 males representing $14.67 \%$ and $85.33 \%$ respectively. The instrument used was 
conceptual and procedural knowledge test in rational numbers. Only one item was adopted from [6] study while the rest of the items were developed by the researcher making a total of 20 questions, 10 each of conceptual knowledge and procedural knowledge in rational numbers as in appendix A. The test items composed of sub-topics, such as the concept of a part of a set, order, fraction equivalence, the concept of a set, processes on fractions, identification of rational numbers, representing rational numbers on the number line, finding reciprocal of rational numbers and reallife application questions on rational numbers. The marking scheme that was used was that of [6] where each item was scored out of 4 marks depending on some benchmark's criterion. The responses were scored on a 5-point scale from no answer (0) to correct answer and algorithm (4). The overall total mark was 80 . The minimum and maximum scores to achieve from each item were 0 and 4 respectively. To ensure the validity of the instrument two experts from the researcher's department in the College and a senior lecturer in
University of Education, Winneba subjected the instrument to both content and face validity. After a week it was cleared for piloting. The pilot study was conducted among level 300 Pre-Service Teachers of one of the researcher's College with 22 pre-service teachers. The results from the pilot test were used to calculate the reliability coefficient using the split-half method which resulted in 0.79 and 0.85 for conceptual knowledge and procedural knowledge respectively, which were good for administering and appropriate enough to achieve the objectives of the main study. The subjects of the study took the conceptual and procedural knowledge test (CPKT) on rational numbers on $11^{\text {th }}$ and $12^{\text {th }}$ December, 2019 respectively. The duration allocated for each test was 1 hour. In analyzing the data, descriptive and inferential statistics were applied in order to answer the four research questions.

To judge the extent to which the Pre-Service Teachers master the levels of conceptual and procedural knowledge, the following categorization: Very Low, Low, Average, and High was used as in Table 1.

Table 1. Mastery levels of conceptual and procedural knowledge.

\begin{tabular}{llll}
\hline Serial No. & $\begin{array}{l}\text { Overall Score range of conceptual } \\
\text { knowledge Test }\end{array}$ & $\begin{array}{l}\text { Overall Score range of procedural } \\
\text { knowledge Test }\end{array}$ & $\begin{array}{l}\text { Mastering level of Conceptual and } \\
\text { Procedural knowledge }\end{array}$ \\
\hline 1 & $31-40$ & $31-40$ & High \\
2 & $21-30$ & $21-30$ & Average \\
3 & $11-20$ & $11-20$ & Low \\
4 & $1-10$ & $1-10$ & Very Low \\
\hline
\end{tabular}

\section{Results}

The purpose of the study was to examine mastery level, achievements differences and correlation between conceptual and procedural knowledge of rational numbers among Pre-Service Teachers of E. P. College of Education, Bimbilla.

Research Question 1: What is the level of Pre-Service Teachers' conceptual knowledge of rational numbers?

Table 2. Cumulative frequency of Pre-Service Teachers' Conceptual Knowledge of Rational numbers.

\begin{tabular}{llll}
\hline Mark & Frequency & Valid Percent & Cumulative Percent \\
\hline 13 & 1 & 1.3 & 1.3 \\
15 & 5 & 6.7 & 8 \\
16 & 7 & 9.3 & 17.3 \\
17 & 17 & 22.7 & 40 \\
18 & 10 & 13.3 & 53.3 \\
19 & 11 & 14.7 & 68 \\
20 & 10 & 13.3 & 81.3 \\
21 & 7 & 9.3 & 90.7 \\
22 & 6 & 8 & 98.7 \\
23 & 1 & 1.3 & 100 \\
Total & 75 & & \\
\hline
\end{tabular}

From Table 2, fifty-one (51) representing 68\% scored below the half mark of 20 in the conceptual knowledge test of rational numbers. Also, 10 (13.3\%) Pre-Service Teachers scored exactly the half mark while 14 Pre-Service Teachers' representing $18.6 \%$ attained marks within the range $21-23$ which is above the half mark in the conceptual knowledge test.

Table 3. Pre-Service Teachers' Conceptual Knowledge Level of Rational numbers.

\begin{tabular}{llll}
\hline Score Range & Level & Number in sample & Percentage in Conceptual Understanding Level \\
\hline $31-40$ & High & 0 & $0 \%$ \\
$21-30$ & Average & 14 & $18.67 \%$ \\
$11-20$ & Low & 61 & $81.33 \%$ \\
$1-10$ & Very Low & 0 & $0 \%$ \\
Total & & 75 & $100 \%$ \\
\hline
\end{tabular}


In determining the conceptual knowledge understanding levels, Table 3 has showed that no Pre-Service Teachers were found in the high and very low levels. Majority of the PSTs were in the low levels representing $81.33 \%$ in the conceptual understanding of rational numbers. However, 14 (18.7\%) of the Pre-Service Teachers were at the average level.

Research Question 2: What is the level of Pre-Service Teachers' Procedural knowledge of rational numbers?

Table 4. Cumulative frequency of Pre-Service Teachers' Procedural Knowledge of rational numbers.

\begin{tabular}{llll}
\hline Mark & Frequency & Valid Percent & Cumulative Percent \\
\hline 20 & 1 & 1.3 & 1.3 \\
21 & 9 & 12 & 13.3 \\
22 & 11 & 14.7 & 28 \\
23 & 11 & 14.7 & 42.7 \\
24 & 6 & 8 & 50.7 \\
25 & 6 & 8 & 58.7 \\
26 & 1 & 1.3 & 60 \\
27 & 7 & 9.3 & 69.3 \\
28 & 1 & 1.3 & 70.7 \\
30 & 19 & 25.3 & 96 \\
31 & 1 & 1.3 & 97.3 \\
32 & 1 & 1.3 & 98.7 \\
34 & 1 & 1.3 & 100 \\
Total & 75 & 100 & \\
\hline
\end{tabular}

As depicted in Table 4, no PST scored below the half mark of 20 in the procedural knowledge test on rational numbers. Also, $1(1.3 \%)$ scored exactly the half mark, while 74 $(98.7 \%)$ scored above the half mark. The minimum and maximum marks obtained were 20 and 34 respectively in the procedural knowledge understanding test. The modal mark was 30 indicating 19 Pre-Service Teachers achieving that in the procedural knowledge test. The range was 14 .

Table 5. Pre-Service Teachers' Procedural Knowledge Level of Rational numbers.

\begin{tabular}{llll}
\hline Score & Level & Number in sample & Percentage in Procedural Understanding Level \\
\hline $31-40$ & High & 3 & $4 \%$ \\
$21-30$ & Average & 71 & $94.67 \%$ \\
$11-20$ & Low & 1 & $1.33 \%$ \\
$1-10$ & Very Low & 0 & $0 \%$ \\
Total & & 75 & $100 \%$ \\
\hline
\end{tabular}

As in Table 5, the Pre-Service Teachers who performed very well in the procedural knowledge test on rational numbers because 3 (4\%), 71 (94.67\%), and 1 (1.33\%) were found at high, average and low levels respectively of procedural knowledge in rational numbers. There was no
Pre-Service Teacher at very low level.

Research Question 3: Is there significant difference between the Pre-Service Teachers' conceptual knowledge and procedural knowledge in rational numbers?

Table 6. Paired Samples Statistics of Pre-Service Teachers' Procedural Knowledge Level of rational numbers.

\begin{tabular}{lllll}
\hline Type of Knowledge & N & Mean & Std. Deviation & Std. Error Mean \\
\hline conceptual knowledge & 75 & 18.40 & 2.18 & .247 \\
procedural knowledge & 75 & 25.44 & 3.64 & .421 \\
\hline
\end{tabular}

Table 7. Paired sample t-test of Pre-Service Teachers' Conceptual knowledge and Procedural Knowledge Level of rational numbers.

\begin{tabular}{lllllll}
\hline Type of Knowledge & Mean & Std. Deviation & Std. Error Mean & df & T & Sig. (2-tailed) \\
\hline conceptual knowledge-procedural knowledge & -7.04 & 4.16 & .48 & 74 & -14.643 & .000 \\
\hline
\end{tabular}

Tables 6 and 7 presents the paired sample t-test of the PreService Teachers' achievements scores in conceptual and procedural knowledge in rational numbers. From Table 6, the mean and standard deviation score of conceptual knowledge was $(\mathrm{M}=18.40 . \mathrm{SD}=2.18)$ while that of the procedural knowledge was $(\mathrm{M}=25.44$. $\mathrm{SD}=3.64)$. Majority of the PreService Teachers' score for conceptual knowledge were between 16.22 and 20.58 while the range of marks for the procedural knowledge was between the range of 21.8 and
29.08. From the analysis in Table 7 , there was significant difference at $\mathrm{t}(74)=-14.643, \mathrm{p}=0.000<0.05$ at 2 -tailed. The significant difference was in favor of the procedural knowledge with a mean difference of 7.04. Hence, the null hypothesis was rejected because there was significant difference in achievement. The effect size of the study was calculated to determine the extent of the differences between the PSTs conceptual and procedural knowledge in rational numbers. Detail calculation is shown below. 


$$
\text { Cohen's } \mathrm{d}=\frac{M_{p-M_{C}}}{\sqrt{\frac{S D_{p}^{2}+S D_{c}^{2}}{2}}}, \mathrm{~d}=\frac{25.44-18.40}{\sqrt{\frac{(3.64)^{2}+(2.18)^{2}}{2}}}, \mathrm{~d}=\frac{7.04}{\sqrt{\frac{13.25+4.75}{2}}}, \mathrm{~d}=\frac{7.04}{\sqrt{\frac{18}{2}}} \mathrm{~d}=\frac{7.04}{\sqrt{9}} \mathrm{~d}=\frac{7.04}{3}, \mathrm{~d}=2.35
$$

Note: $M_{p=\text { Mean of } \text { procedural knowledge }}, M_{c=\text { Mean of } \text { conceptual knowledge }}$,

$$
S D_{p}=S t d \text {. Deviation of procedural knowledge } S D_{c}=S t d \text {. Deviation of conceptual knowledge }
$$

The Cohen's d of (2.35) indicates very high effect size, signifying that $235 \%$ of the variance in their scores on conceptual and procedural knowledge in rational numbers favored the procedural knowledge.
Research Question 4: Is there significant correlation between Pre-Service Teachers' conceptual knowledge and their procedural knowledge regarding rational numbers?

Table 8. Bivariate Correlations of Pre-Service Teachers' Conceptual knowledge and Procedural Knowledge Level of rational numbers.

\begin{tabular}{llll}
\hline & & Conceptual knowledge & Procedural knowledge \\
\hline & Pearson Correlation & 1 & .033 \\
conceptual knowledge & Sig. (2-tailed) & & .781 \\
& $\mathrm{~N}$ & 75 & 75 \\
& Pearson Correlation & .033 & 1 \\
procedural knowledge & Sig. (2-tailed) & .781 & 75 \\
& $\mathrm{~N}$ & 75 & 75 \\
\hline
\end{tabular}

Table 8 was used to answer research question 4 on whether there is a correlation between Pre-Service Teachers' conceptual knowledge and procedural knowledge of rational numbers.

As displayed in Table 8, the test of hypothesis at 0.05 significant level found a weak correlation between the PreService Teachers' conceptual knowledge and procedural knowledge in rational numbers. Thus, per this study, even though there is a weak positive correlation between PreService Teachers' conceptual knowledge and procedural knowledge in rational numbers, the correlation is also not significant at $(\mathrm{r}(75)=.033, \mathrm{p}=.781>.05)$. Hence, the null hypothesis is upheld implying there is no statistically significant relationship between Pre-Service Teachers' conceptual knowledge and procedural knowledge in rational numbers.

\section{Discussion}

This study examined mastery level, achievements differences, and correlation of Pre-Service Teachers' conceptual and procedural knowledge of rational numbers.

Discussion on conceptual knowledge

For research question one, which sought to determine the Pre-Service Teachers' conceptual knowledge of rational numbers understanding levels, majority $(81.33 \%)$ were at a low level, and $18.6 \%$ were at average level. The PSTs performed creditably in giving precise definitions to rational number, fraction, numerator and denominator. Only a few of them got confused about the definitions of rational number and fraction. For question one, the PSTs performed creditably in giving the precise definitions to rational numbers, fractions, numerators and denominators. Majority (68\%) of the PSTs also exhibited good understanding in subtracting two mixed fractions because few mistakes were recorded, hence question two was well answered. From the script analysis majority (51\%) of the PSTs could not answer questions 3a. They were rather subtracting the age of the cat from the age of the dog which was a wrong approach.

From the script analysis, majority (59\%) of the PSTs could not answer question $4 \mathrm{a}$ which required them to sketch 1 whole, when given $\frac{2}{3}$. Some of them left it unanswered and those who attempted it got it wrong because they had multiplied the reciprocal of $\frac{2}{3}$ and simplified it as $\frac{2 \times 3}{3 \times 2}=1$. However, the remaining of the PSTs just added $\frac{1}{3}$ to $\frac{2}{3}$ to get $\frac{3}{3}$ $=1$ whole. These PSTs were not able to explain with any tangible reason to back their answers. Question $4 \mathrm{~b}$ was yet another question that exposed the PSTs conceptual understanding because the question asked them to represent 1 whole by a sketch, when given $\frac{5}{4}$. Most of them attempted it but got it wrong because they failed to understand that $\frac{5}{4}=\frac{1}{4}+$ $\frac{1}{4}+\frac{1}{4}+\frac{1}{4}+\frac{1}{4}$. The correct approach required them to divide the line segment into 5 equal parts and take away one-fourth part to denote that $\frac{4}{4}=1$. Question $4 \mathrm{c}$ further exposed the PSTs lack of conceptual knowledge of rational numbers, because they failed to workout question 4c correctly. Question 4c demanded the PSTs to represent $\frac{2}{3}$ when given $\frac{5}{4}$ of a line segment. For this question the PSTs needed to partition each small line segment into 3 parts equally adding up to 12 equal boxes and shade 8 of the 12 boxes, which is equivalent to $\frac{2}{3}$. Also, no PST attempted question $4 \mathrm{~d}$, which required them to sketch $\frac{3}{5}$ when given a figure that represents $\frac{5}{3}$. Question 5 was excellently answered because majority (86\%) of the PSTs were able to identify the solved problem errors. They stated that Rizka simplified the problem by just adding the numerators and denominators to obtain $\frac{5}{9}$. They also gave correct reasons to support the alternative solved problem as in the question. Also, majority (74\%) of the PSTs performed 
creditably in drawing wholes when given parts as in question $6 \mathrm{a}$ and $6 \mathrm{~b}$. The reverse was questions $6 \mathrm{c}$ and $6 \mathrm{~d}$ where parts were given for the PSTs to draw the wholes. These questions were poorly answered because the PTSs could not comprehend and hence gave wrong drawings as their answers. The correct representation for question $6 \mathrm{c}$ was four dots, since 2 dots were $1 / 5$. The correct answer for $6 \mathrm{~d}$ was 8 dots since 2 dots represent $1 / 3$. Question 7 was also partly answered correctly because majority (52\%) could explain their reason with diagrams whiles others could not explain their reasons correctly. Question 8a was well answered because the PSTs understood the questions and gave accurate drawings of the leftover as 6 pieces of chocolate. The PSTs made use of the idea of continuous take-way approach or subtraction in mathematics to get the correct answer. However, the second part of the question that demanded PSTs estimate rational numbers on given number lines was poorly answered because majority (51\%) of the PSTs could not mark $1 \frac{1}{7}$ and $1 / 3$ on the given number lines. Questions $9 \mathrm{a}$ and $9 \mathrm{~b}$ were poorly answered by some of the PSTs because they resorted to formulas instead of using simple logic. i.e speed $=\frac{\text { Time }}{\text { Distance }}$ which is a wrong formular used for question 9a.

Question 10 was the second toughest of the entire test, hence majority $(90 \%)$ of the PSTs could not explain their answers. Over $90 \%$ of the PSTs performed calculation first before giving their answers which the question clearly stated that PSTs should not calculate. The PSTs lack the concept of the relationship between numerator and denominator to give you one whole.

From the scripts again, the PSTs responses showed that they did not just understand the conceptual knowledge questions. This performance shows that most of the PreService Teachers lacked conceptual knowledge of rational numbers because no PST attained a high level. This study is similar to [11] who also stated that the majority of her subjects were at low mastery level of conceptual and procedural knowledge. Similar to this study also is [16] who found that students performed poorly in his study by emphasizing that students lacked sufficient comprehension of conceptual knowledge. This is a disturbing phenomenon because it is the expectation of all the stakeholders in Ghanaian educational system that PSTs will have the conceptual knowledge of all the mathematics topics including rational numbers to be able to handle the mathematics syllabus in the basic schools. This indicates that, the Pre-Service Teachers experienced challenges in relating different parts of their schemata to workout questions that were not straightforward but demanded application or analysis domain. This is not also good because inadequate conceptual knowledge will render these PSTs lessons in Mathematics difficult, boring and increased their pupils' misconceptions in Mathematics in general. Finally, [1] findings tally with this study's findings, where he also indicated that students are not able to apply or make inferences when they are confronted with new situations or problems. Majority of the Pre-Service Teachers' justifications for their answers were not straight to the point, hence corresponded with [7], who stated that students struggled in providing explanations concerning the Mathematical rules or procedures that they used as they learned Mathematics.

It was clear that the PSTs lacked conceptual understanding of rational numbers which also collaborated with their poor achievements and mastery levels in conceptual knowledge because some of the PST's approach to the questions were wrongly presented. A careful look at the Ghanaian textbooks shows that learning opportunities focuses on procedural knowledge which could account for PSTs poor performance in conceptual knowledge.

\section{Discussion on procedural knowledge}

For the procedural knowledge test on rational numbers which sought to examine the mastery level was research question two. The Pre-Service Teachers depended on procedures and algorithms to solve the question using a routine method. Question 1 was excellently answered by the PSTs but only 3 PSTs had difficulty in solving 1a because they had problem using the "invert and multiply" approach. PSTs also scored the full marks for question 2 and 3 which demanded them to fill the blank spaces as in question 2 and arrangement of rational numbers in ascending order for question 3. Question 4 was also properly answered because they were able to convert mixed fraction to improper fraction and subtract and add the given variable constant to both sides. Also, question 5 and 6 were correctly answered. The PSTs exhibited better way of solving subtraction and multiplication of fractions. Question $7 \mathrm{~b}$ was nicely answered because the PSTs had mastered the concept of reciprocal of whole numbers and rational numbers. The performance of $8 \mathrm{a}$ was far better than $8 \mathrm{~b}$. This was due to the fact that $8 \mathrm{a}$ contained brackets whiles $8 \mathrm{~b}$ did not. The poor performance in $8 \mathrm{~b}$ was as a result of some PSTs not obeying BODMAS rule in solving questions. Question 9 was perfectly answered because the PSTs were able to draw number lines and indicated the rational number on it. Question $10 \mathrm{~b}$ was well answered because the PSTs were able to identify rational numbers from fractions and whole numbers, question 10a demanded PSTs to find the $1^{\text {st }} 7$ (seven) rational numbers between $1 / 3$ and $1 / 2$. Some of the PSTs just added and subtracted the rational numbers to arrive at $5 / 6$ and $-1 / 6$ as their answers. But the correct solution should have been as follows:

$$
\frac{1}{3}=\frac{1 \times 30}{3 \times 30}=\frac{30}{90} \text { and } \frac{1}{2}=\frac{1 \times 45}{2 \times 45}=\frac{45}{90}
$$

Therefore, the $1^{\text {st }} 7$ rational numbers between $\frac{30}{90}$ and $\frac{45}{90}$, are as follows $\frac{31}{90}, \frac{32}{90}, \frac{33}{90}, \frac{34}{90}, \frac{35}{90}, \frac{36}{90}$ and $\frac{37}{90}$.

For instance, almost all the Pre-Service Teachers resorted to the "invert and multiply" method in solving the division of fractions questions. This finding tallies with [6], where he indicated that pre-service teachers only relied on the "invert and multiply" method. This is evident that those Pre-Service Teachers do not have an in-depth knowledge of the division 
operation when it involves fractions. Hence, it goes a long way to suggest that some of the Pre-Service Teachers' do not have the basics in solving multiplication and division operations of fractions. However, the Pre-Service Teachers' performance was good because majority (98.67\%) attained high - average levels. This study corresponds to $[6,14]$ and [30] studies that have confirmed better mastery level and achievements of procedural knowledge. Finally, after marking the scripts, it was clear that the PSTs demonstrated good procedure to working the questions correctly. This could be due to their familiarity of procedural knowledge questions from the basic level to senior high level.

From the analysis, there was a significant difference in the Pre-Service Teachers' conceptual knowledge and procedural knowledge in rational numbers, which was in favor of the procedural knowledge. The finding in this study is parallel to the findings by [18] and [28] who found that students did better in procedural knowledge as compared to that of their conceptual knowledge. This study is however contrary to [5] who found that students exhibited a high confidence level in conceptual knowledge than procedural knowledge problems. It was clear from research question four that, there was a weak positive correlation between the Pre-Service Teachers' conceptual knowledge and procedural knowledge in rational numbers. The correlation was also not significant at 0.05 alpha level which implies that the relationship of the PSTs' conceptual knowledge and procedural knowledge in rational numbers is weak. This study tallies with that of [15] who also concluded that there was a weak positive correlation between teachers' conceptual knowledge and their procedural knowledge concerning rational numbers achievements test. This study also corroborates with the findings of [4] that revealed a positive correlation between content knowledge and pedagogical content knowledge. However, this study differs from [15] again on the issue of a significant relationship between conceptual knowledge and procedural knowledge.

\section{Conclusion}

The Pre-Service Teachers' conceptual knowledge and procedural knowledge mastery levels were at average-low and high-average levels respectively. Also, there was a significant difference in achievements between conceptual and procedural knowledge in rational numbers in favor of the procedural knowledge. There was a weak positive correlation and no significant relationship between the Pre-Service Teachers' conceptual knowledge and procedural knowledge in rational numbers.

\section{Recommendation}

Based on the findings of this study, the following recommendations were made:

1. Pre-Service Teachers' conceptual knowledge on rational numbers should be enhanced to meet the changing trends in the Ghanaian educational sector needs.
2. College Tutors should be encouraged to adopt teaching methods and strategies that focus on conceptual knowledge in rational numbers.

3. College Tutors should concentrate more on the conceptual knowledge on rational numbers because PSTs' performance on the procedural knowledge was far better.

4. College Tutors evaluation exercises or assessment items should be balanced between conceptual knowledge and procedural knowledge because at the moment most assessment items are based on procedural knowledge to the neglect of conceptual knowledge assessment.

5. Stakeholders of the Colleges of Education such as Transforming Teacher Education and Learning ( $\mathrm{T}$ TEL), affiliated University and Ministry of Education should ensure that College tutors go strictly by the 2018 new curriculum which place emphasis on more conceptual knowledge than the procedural knowledge.

6. The Ministry of Education, affiliated University, and Colleges of Education should organize and sponsor Mathematics workshops and conferences aimed at refreshing tutors' conceptual and procedural knowledge in Mathematics more especially rational numbers.

7. Textbook writers should include enough conceptual knowledge work examples in textbooks across all levels of education ladder.

\section{Appendix}

\section{E. P. COLLEGE OF EDUCATION, BIMBILLA}

Conceptual knowledge test on rational numbers

Answer all questions Duration 1 hour

Date: $11^{\text {th }}$ December, 2019

(1) Explain the following: (i) Rational number, (ii) Fraction, (iii) Numerator, (iv) Denominator

(2a) You are trying to be more diligent about drinking enough water during the day. Base on your body weight it is recommended that you drink $8 \frac{2}{3}$ glasses of water. If you have already had $3 \frac{1}{3}$ of the second one. How much more do you have left to drink

(2b) We recently repainted the living areas in our home. We overestimated the paint we needed so we had $2 \frac{1}{3}$ gallons of paint left over. If we use another $1 \frac{1}{6}$ gallons to paint the master bathroom, how much paint we have left for touch up?

(3a) My dog is $3 \frac{3}{4}$ years old and my cat is $2 \frac{3}{8}$ years older than my dog. How old is my cat?

(3b) What happens to this fraction $\frac{9}{8}$, if the numerator is increased by three folds and the denomination is divided by 4 ?
(4) A. Given $\frac{2}{3}$ represent 1 whole
B. Given $\frac{5}{4}$ represent 1 whole
C. Given $\frac{5}{4}$ represent $\frac{2}{3}$
D. Given $\frac{5}{3}$ represent $\frac{3}{5}$ 
(5a) Rizka solved the following addition operation like this $\frac{(3+2)}{6+3}=\frac{5}{9}$. Whereas, Hifza solved the same operation and found $\frac{3}{6}+\frac{2}{3}=\frac{(3+4)}{6}=\frac{7}{6}$. Which of the solution is correct?

Why? Explain your reasoning.

(6a) Ali ate $\frac{3}{4}$ of a chocolate bar. What is then left of the chocolate is given below. Make a drawing of how big the chocolate bar was before Ali ate any.

(6b) This $\triangle \triangle \triangle \triangle \triangle \triangle \triangle \triangle \triangle \triangle \Delta^{3} \frac{3}{4}$ of a whole. Draw the whole.

(6c) The counters below represent $2 \frac{4}{5}$ of the counters. Circle $\frac{2}{5}$ of the counters.

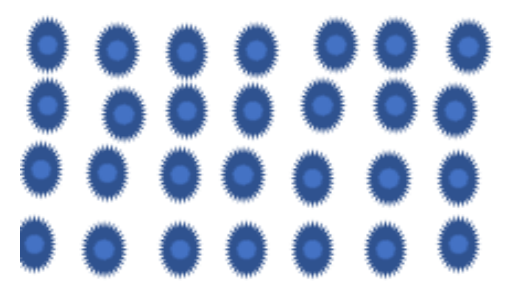

(6d) These counters represent $\frac{2}{3}$ of the counters. Draw $1 \frac{1}{3}$ of the counters.

(7) Ali and his friend Gadafi decided to buy a slice of pizza. Pizza boy said that there were only half of a pizza and $\frac{1}{3}$ of another pizza and added that they should wait for a time for new pizza. Since Ali was hungry, he wanted the half pizza and Gadafi bought $\frac{1}{3}$ pizza. However, they realized that Gadafi's pizza slice was bigger than Ali's. Do you think this is possible? Explain your reasons.

(8a) The diagram below represents Safura's chocolate bar.

Safura gave $\frac{1}{4}$ of her chocolate bar to her husband and saved the rest for herself. After dinner she ate $\frac{1}{3}$ of the part she saved for herself. Draw a diagram to represent the leftover chocolate after her dinner.

\begin{tabular}{|l|l|l|l|l|l|}
\hline & & & & & \\
\hline & & & & & \\
\hline
\end{tabular}

(8b) (i) Mark $1 \frac{1}{7}$ on the number line below.

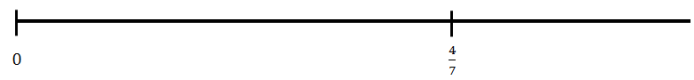

(8b) (ii) Mark $\frac{1}{3}$ on the number line below.

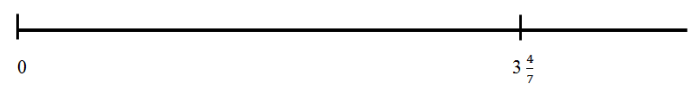

(9a) On a highway a car travels 2 miles in 3 minutes. If the speed of the car is constant, how far does it travel in 20minutes? (9b) A designer is in need of $3 \frac{3 / 4}{4}$ rolls of a wall paper to decorate a room. how many rooms can be decorated using 13 rolls of the same paper?

(10a) Estimate the following addition without any calculation $\frac{12}{13}+\frac{7}{8}$. Which integer is it close to? Explain your answer convincingly.

E. P. COLLEGE OF EDUCATION, BIMBILLA

Procedural knowledge test on rational numbers Answer all questions Duration: 1 hour

Date: $12^{\text {th }}$ December, 2019

(1) Solve the following fractions

$$
\begin{aligned}
& 13 / 4 \div 1 / 2 \\
& 13 / 4 \times 1 / 2 \\
& 13 / 4-1 / 2 \\
& 13 / 4+1 / 2
\end{aligned}
$$

(2) Complete the blank spaces

$$
\text { (a) } \frac{8}{14}=\frac{-}{21} \text { (b) } \frac{3}{8}=\frac{12}{12} \text { (c) } \frac{8}{15}=\frac{-}{5} \text { (d) } \frac{6}{18}=\frac{-}{5}
$$

(3) Rearrange the following in ascending order.

$$
\frac{2}{3}, \frac{16}{31}, \frac{9}{19}, \frac{11}{12}, \frac{3}{4}, \frac{9}{21}, \frac{5}{12}, 0.997
$$

(4) Find the fractions represented by letters in the operations below

$$
\begin{aligned}
& 1 \frac{1}{8}+a=2 \frac{3}{8} \\
& \frac{9}{10}-b=\frac{4}{5}
\end{aligned}
$$

(5a) what is the solution of the subtraction

$$
1 \frac{7}{10}-\frac{2}{4}
$$

(5b) what is the solution of the multiplication

$$
\frac{5}{6} \times \frac{3}{4}
$$

(6) Find the values of $a, b$, and c given in the fractions below.

$$
\begin{array}{ll}
\text { (a) } \frac{1}{3}=\frac{2}{a}=\frac{b}{15}=\frac{4}{c} & \text { (b) } \frac{6}{13} \times \frac{13}{12}=?
\end{array}
$$

(7a) What is the solution of the following operation?

$$
\left(3-1 \frac{1}{3}\right): \frac{2}{5}
$$

(7b) Find the reciprocal of the following rational numbers:

$$
\text { (i) } \frac{-3}{4} \text { (ii) } 0 \text { (iii) } \frac{6}{11} \text { (iv) } \frac{-5}{9}
$$

(8) Solve (a) $\left(\frac{3}{5}-\frac{5}{6}\right) \times\left(1 \frac{2}{3}+\frac{7}{3}\right)$ (b) $\frac{-4}{5} \times \frac{3}{4}+\frac{4}{5} \times \frac{3}{7}$

(9) Represent the following rational number on number lines 


$$
\text { (a) } \frac{-2}{3} \text { (b) } \frac{3}{4} \text { (c) } \frac{3}{2} \text { (d) } \frac{-5}{2}
$$

(10) Find 7 rational numbers between (a) $\frac{1}{3}$ and $\frac{1}{2}$, (b) pick rational numbers from the following

$$
\frac{6}{7}, \frac{-1}{2}, 0, \frac{1}{0}, \frac{100}{0}, \frac{14}{12}, \frac{11}{3}
$$

\section{References}

[1] Al Selouly, Misfer bin Saud (2013). Conceptual Knowledge Questionnaire Regarding Differentiation among Mathematics Teachers in Secondary Cycle. Pedagogical and Psychology Message - Saudi Arabia 40: 41-57.

[2] Brown, B. (2015). The relational nature of rational numbers, Pythagoras, 36 (1), 273-281.

[3] Chinnappan, M. \& Forrester, T. (2014). Generating procedural and conceptual knowledge of fractions by pre-service teachers. Mathematics Education Research Journal, 26 (4), 871-896. https://ro.uow.edu.au/sspapers/1342

[4] Depaepe, F., Torbeyns, J., Vermeersch, N., Janssens, D., Janssen, R., Kelchtermans, G., Lieven Verschaffel, L., \& Dooren, W. (2014). Teachers' content and pedagogical content knowledge on rational numbers: A comparison of prospective elementary and lower secondary school teachers, Teaching and Teacher Education, 47, 83-92.

[5] Engelbrecht, J., Harding, A., \& Potgieter, M. (2005). Undergraduate students' performance and confidence in procedural and conceptual mathematics. International journal of mathematical education in science and technology, 36 (7): 701-712. DOI: 10.1080/00207390500271107.

[6] Faulkenberry, E. (2003). Secondary mathematics preservice teachers' conceptions of rational numbers. Unpublished Doctoral Dissertation, Oklahoma State University, Oklahoma.

[7] Flores, D. (2002). "Profound understanding of division of fractions". In B. Litwiller, \& G. Bright (Eds), Making Sense of Fractions, Ratios, And Proportions, (pg 237-246). National Council Of Teachers Of Mathematics, Reston, Va.

[8] Hallett, D., Nunes, T. and Bryant, P. (2010). Individual differences in conceptual and procedural knowledge when learning fractions. Journal of Educational Psychology, 102 (2): 395-406. DOI: 10.1037/a0017486.

[9] Hallett, D., Nunes, T., Bryant, P., \& Thorpe, C. M. (2012). Individual differences in conceptual and procedural fraction understanding: The role of abilities and school experience. Journal of Experimental Child Psychology, 113 (2012) 469 486 DOI: 10.1016/j.jecp.2012.07.009.

[10] Hope, M. (2006). Preservice teacher procedural and conceptual understanding of fractions and the effects of inquiry based learning on this understanding. Unpublished Doctoral Dissertation. Clemson University.

[11] Ibrahim, N. (2003). Pedagogical content knowledge of mathematics teacher in algebra. Master of Education, Research Project. Bangi: Universiti Kebangsaan Malaysia.

[12] İșleyen, T., \& Ișık, A. (2003). Conceptual and procedural learning in mathematics. Journal of the Korea Society of
Mathematical Education (Series D: Research in mathematical education), 7 (2), 91-99.

[13] Institute of Education (2016). Chief Examiners' Report on Semester Examinations for Colleges of Education, Ghana. Cape Coast.

[14] Kashim, R. M. (2016). The conceptual and procedural knowledge in rational numbers in primary school teachers. International Journal of Educational and Pedagogical Sciences, 10, (3).

[15] Khashan, K. H. (2014). Conceptual and procedural knowledge of rational numbers for Riyadh elementary school teachers. Journal of Education and Human development, 3 (4), 181- 197. http://jehdnet.com/journals/jehd/Vol_3_No_4_December_2014/ 17.pdf

[16] Mahir, N. (2009). Conceptual and procedural performance of undergraduate students in integration. International Journal of Mathematical Education in Science and $\begin{array}{llll}\text { Technology, } & 40 & \text { (2), } & 201-211 .\end{array}$ https://doi.org/10.1080/00207390802213591

[17] McGehee, J. J. 1990. Prospective secondary teachers' knowledge of the function concept. Unpublished Doctoral Dissertation, University of Texas, 1989.

[18] Miqdadi, R.; Malkawi, A., \& Al Zoughbi, A. (2013). Conceptual Knowledge and Procedural Knowledge Regarding Fractures and Their Relationship to Students / Teachers Concerns For Mathematics. Studies -Pedagogical Sciences 40 (2): $1555-1570$.

[19] Ministry of Education (MOE) (2019). Mathematics Curriculum for primary schools (basic 4 - 6). Accra: National Council for Curriculum and Assessment.

[20] National Research Council. (2001). Adding it up: Helping children learn mathematics. J. Kilpatrick, J. Swafford, and B. Findell (Eds.). Mathematics Learning Study Committee, Center for Education, Division of Behavioral and Social Sciences and Education. Washington, DC: National Academy Press.

[21] Nunes, T., Bryant, P., Barros, R., \& Sylva, K. (2012). The relative importance of two different mathematical abilities to mathematical achievement. British Journal of Educational Psychology, 82, 136-156. DOI: 10.1111/j.20448279.2011.02033.x.

[22] Rittle-Johnson, B. \& Schneider, M. (2012). Developing Conceptual and Procedural Knowledge of Mathematics. In R. Cohen Kadosh \& A. Dowker (Eds.), Oxford handbook of numerical cognition. Oxford University Press.

[23] Schneider, M., \& Stern, E. (2010a). The developmental relations between conceptual and procedural knowledge: A multi-method approach. Developmental Psychology, 46, 178192. doi: $10.1037 / \mathrm{a} 0016701$.

[24] Star, J. R. (2005). Reconceptualizing procedural knowledge. Journal for Research in Mathematics Education, 36, 404-411. DOI: $10.2307 / 30034943$.

[25] Star, J. R. (2016). Small steps forward: Improving mathematics instruction incrementally. Phi Delta Kappan, 97, 58-62. https://doi.org/10.1177/0031721716641651

[26] Stump, S. L. (1996). Secondary mathematics teachers' knowledge of the concept of slope. Unpublished Doctoral dissertation, Illinois State University. DAI-A, 58 (2): 408. 
[27] Tirosh, D. (2000). Enhancing prospective teachers' knowledge of children's conceptions: The case of division of fractions. Journal for Research in Mathematics Education, 31 (1): 5-25. https://www.jstor.org/stable/749817

[28] H. Van Steenbrugge, E. Lesage, M. Valcke \& A. Desoete (2014) Preservice elementary school teachers' knowledge of fractions: a mirror of students' knowledge?, Journal of Curriculum Studies, 46: 1, 138-161, DOI: 10.1080/00220272.2013.839003.
[29] Zakaria, E. and Zaini, N. (2009). Conceptual and Procedural Knowledge of Rational Numbers in Trainee Teachers. European Journal of Social Sciences, 9 (2): 202-217. 38.

[30] Zuya, H. E. (2017). Conceptual and procedural knowledge in mathematics: The Case of Mathematics. American Journal of Educational Research, 5 (3), 310-315. https://doi.org/10.12691/education-5-3-12 